\title{
Induced pluripotent stem cell-based modeling of neurodegenerative diseases: a focus on autophagy
}

\author{
Johannes Jungverdorben ${ }^{1,2}$ (D) - Andreas Till ${ }^{1,3}$ (D) Oliver Brüstle $^{1}$
}

Received: 25 January 2017 /Revised: 30 March 2017 / Accepted: 10 April 2017 /Published online: 7 June 2017

(C) The Author(s) 2017. This article is an open access publication

\begin{abstract}
The advent of cell reprogramming has enabled the generation of induced pluripotent stem cells (iPSCs) from patient skin fibroblasts or blood cells and their subsequent differentiation into tissue-specific cells, including neurons and glia. This approach can be used to recapitulate diseasespecific phenotypes in classical cell culture paradigms and thus represents an invaluable asset for disease modeling and drug validation in the framework of personalized medicine. The autophagy pathway is a ubiquitous eukaryotic degradation and recycling system, which relies on lysosomal degradation of unwanted and potentially cytotoxic components. The relevance of autophagy in the pathogenesis of neurodegenerative diseases is underlined by the observation that disease-linked genetic variants of susceptibility factors frequently result in dysregulation of autophagic-lysosomal pathways. In particular, disrupted autophagy is implied in the accumulation of potentially neurotoxic products such as protein aggregates and their precursors and defective turnover of dysfunctional mitochondria. Here, we review the current state of iPSC-based assessment of autophagic dysfunction in the context of neurodegenerative disease modeling. The collected data show that iPSC technology is capable to reveal even subtle alterations in subcellular homeostatic processes, which form the molecular basis for disease manifestation.
\end{abstract}

Keywords Disease modeling $\cdot$ iPS cells $\cdot$ Neurodegenerative disease $\cdot$ Autophagy

Oliver Brüstle

brustle@uni-bonn.de

1 Institute of Reconstructive Neurobiology, University of Bonn Medical Faculty, Sigmund-Freud-Straße 25, 53105 Bonn, Germany

2 Sloan-Kettering Institute for Cancer Research, 1275 York Avenue, New York, NY 10065, USA

3 LIFE \& BRAIN GmbH, University of Bonn, Sigmund-Freud-Strasse 25, 53105 Bonn, Germany

\section{Introduction}

"We have colonies." and "We realized we had almost the entire pathway in our hands." Two statements that changed the world of life sciences within less than a 15 -year-timespan $[1,2]$.

The first statement refers to the colonies discovered by Kazutoshi Takahashi in Shinya Yamanaka's small research group at Kyoto University in Japan back in 2006. The colonies were the result of 24 carefully chosen genes introduced via retroviruses into skin fibroblasts from mice, reprogramming them into what we now call induced pluripotent stem cells (iPSCs). In the weeks to come, the essential genes for the reprogramming process could be narrowed down to the four transcription factors Oct4, Sox2, Klf4, and c-Myc [3]. A few months later, this revolutionizing approach was successfully translated to human cells $[4,5]$.

Pluripotent stem cells (PSCs) have the potential to differentiate into derivatives of all three germ layers, thus providing a route to generate any somatic cell type in limitless numbers in vitro. Unlike pluripotent embryonic stem cells, iPSCs can be derived from any patient or healthy donor, thereby opening unprecedented prospects for generating autologous donor cells for regenerative medicine, patient-specific disease models, and drug discovery (Fig. 1). In 2012, not even a decade after the first description of the first iPSCs, Shinya Yamanaka was awarded the Nobel Prize for this revolutionizing breakthrough together with Sir John B. Gurdon, who had shown reprogramming by nuclear transfer in Xenopus oocytes decades before [1].

The second statement refers to the discovery Yoshinori Ohsumi and his group in Tokyo made in 1993 when they discovered 15 genes in yeast that were essential for the autophagic process [6] which is induced in yeast mainly upon starvation. The term "autophagy" (from Greek $\alpha$ v่ ó-/auto = „self-“and $\varphi \propto \gamma \varepsilon \tilde{\varepsilon}$ /phageín = ,eating") was introduced by Christian de Duve in 1963 [7] as an umbrella term for the delivery of cytoplasmic material to lysosomes (or the vacuole in plants or fungi) for degradation. (For clarity on terminology used in this review, Textbox 1 provides an overview on autophagy-related terms, 


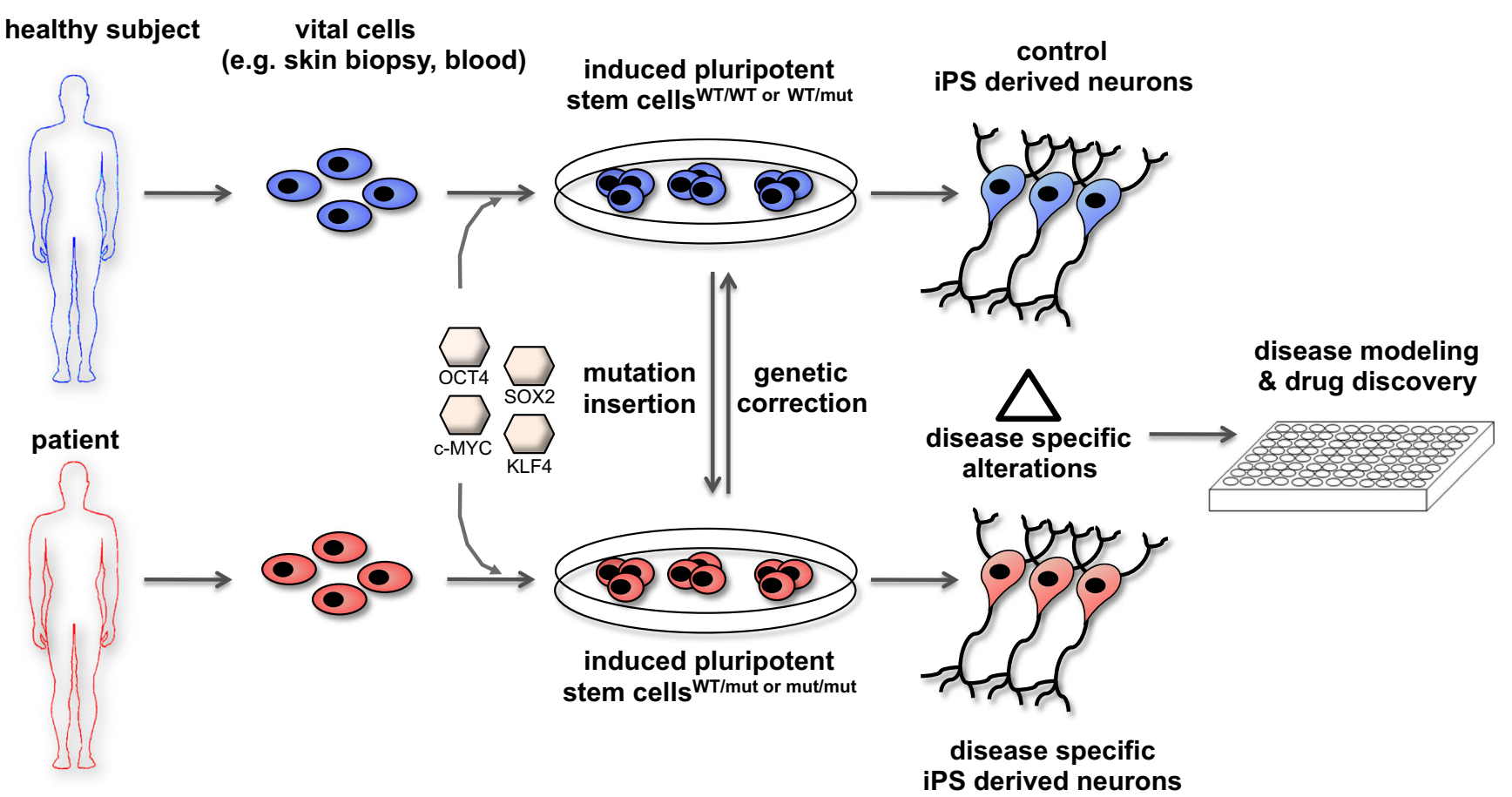

Fig. 1 Generation of control and patient-specific iPSCs and their differentiation into neurons and glia for assessment of disease-specific alterations. Cells collected from healthy donors or affected patients (e.g., skin fibroblasts or blood cells) are reprogrammed to a pluripotent state by introduction of the transcription factors OCT4, SOX2, KLF4, and c-MYC ("Yamanaka factors"). Isogenic controls can be generated via genetic correction (e.g., genome editing) of the disease-related

definitions, and methodology.) Today autophagy is subclassified into four variants: microautophagy [8], chaperone-assisted selective autophagy (CASA) [9], chaperone-mediated autophagy (CMA) [10, 11], and macroautophagy. The best-studied subclass in the mammalian system, macroautophagy (hereafter referred to as autophagy), is a process where a double membrane cup-shaped structure, the phagophore, forms to engulf a portion of the cytosol including protein aggregates, entire or parts of organelles and intracellular pathogens, and after closure delivers the cargo as mature autophagosome by fusion to lysosomes for degradation [12]. The genes discovered by Ohsumi and colleagues, nowadays called Atgs (Autophagy related genes), cover essentially the whole molecular machinery required for this process. In the years to follow, his group deciphered the precise mode-of-action of a large variety of previously uncharacterized Atgs, which turned out to form a ubiquitin-like conjugation and a lipidation system. Specifically, Atg12 was found to be a ubiquitin-like protein that is activated at its C-terminus by the E1 enzyme Atg7 and transferred to the E2 enzyme Atg10 before being covalently linked to Atg5 [13]. This Atg12-Atg5 conjugate, together with Atg16, then forms a complex essential for autophagy [14, 15], a process also conserved in mammalian cells $[16,17]$. The second system for lipidation is composed of Atg8 as a precursor that is cleaved by mutation. Conversely, disease-associated mutations can be inserted into iPSCs generated from healthy subjects to yield disease-specific iPSCs. Neural cells derived from control and disease-specific iPSCs are then used to decipher cellular and molecular alterations associated with the disease process ("disease modeling"). Neural cells generated this way may also be used for compound testing and drug discovery in a celland disease-specific human context

the cystein protease Atg4, then activated and transferred by the E1 enzyme Atg7 to the E2 enzyme Atg3 and finally covalently bound to the lipid phosphatidylethanolamine (PE) [18]. Again, this system was found to be conserved in mammals, and the mammalian homolog of Atg8, LC3, is also cleaved by ATG4 to LC3-I and further processed by ATG7 and ATG3 to form lipidated LC3-II that is stably integrated into the membrane of the growing autophagosome [19] (Fig. 2). Detection of LC3-II provided the first reliable marker for mammalian autophagosomes, and its abundance correlates with autophagosome number [20]. The importance of autophagy in neuronal homeostasis was demonstrated only a few years later by Noboru Mizushima, a former postdoc of Ohsumi, and Komatsu et al. by CNS-specific conditional targeting of Atg5 and Atg7, respectively. Affected mice showed neurodegeneration, motor impairment, and formation of ubiquitin-positive intraneuronal protein inclusions [21, 22]. Since then, the role of defective autophagy as a key player in neurodegeneration [23] (Fig. 3), cancer [24], and aging [25] gained more and more attention. In 2016, Yoshinori Ohsumi was awarded the Nobel Prize for his seminal discovery. 


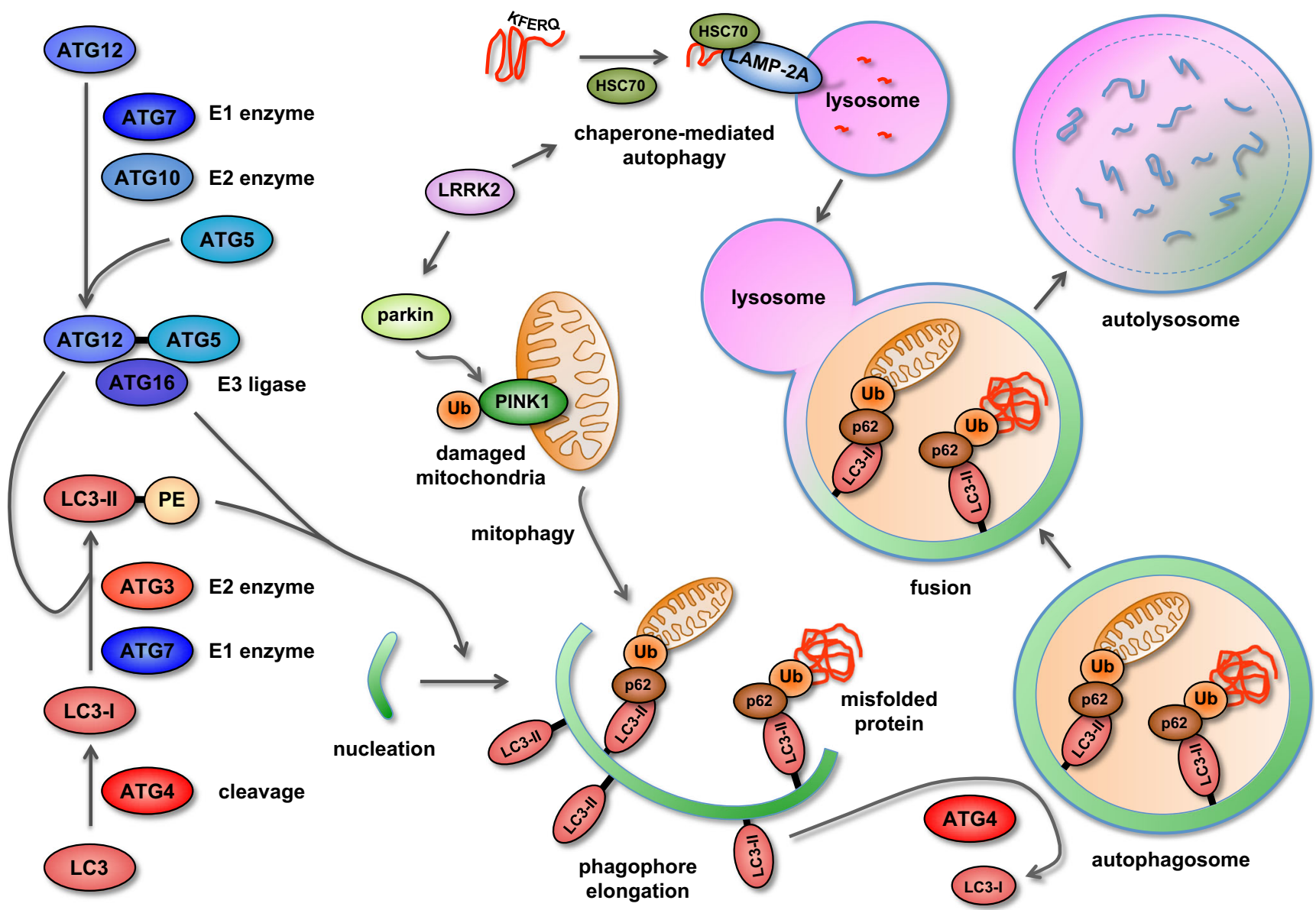

Fig. 2 Regulation and execution of the autophagosomal-lysosomal degradation pathway. Two ubiquitin-like conjugation systems are involved in the regulation of autophagy. ATG12, a ubiquitin-like protein, is covalently bound to ATG5 by the E1 and E2 enzymes ATG7 and ATG10, respectively. In parallel, LC3 is cleaved by ATG4, primed by the E1 and E2 enzymes ATG7 and ATG3 to be covalently linked to the lipid phosphatidylethanolamine (PE) by the E3 ligase complex ATG12/5/16 to generate the processed, lipid-bound form of LC3, LC3-II. LC3-II and the ATG12/5/16 complex act together in the elongation and finally closure of the phagophore. LC3-II also acts as anchor on the inner membrane for adaptor proteins such as p62 that recognize ubiquitinated substrates, e.g., misfolded proteins or damaged organelles. On aged or dysfunctional mitochondria, PINK1 localizes to the outer membrane, where it is

In this review, we focus on the interface between these two Nobel Prize-awarded advances and present recent progress in using iPSCs for studying autophagy-related phenotypes in neurodegenerative disease.

\section{Parkinson's disease}

Parkinson's disease (PD) is the second most common neurodegenerative disorder affecting $2 \%$ of the population over the age of 60 [26]. Prominent symptoms of PD include motor deficits like tremor, bradykinesia, and limb rigidity. The neuropathology recognized and ubiquitinated by the E3 ubiquitin ligase parkin. Ubiquitinated PINK1 recruits autophagy receptors such as p62 and renders the mitochondria attractive for degradation by autophagy ("mitophagy"). After closure, the autophagosome with its cargo is primed for fusion with lysosomes, which is accompanied by removal and recycling of LC3-II by ATG4. The resulting autolysosome degrades the cargo and releases the components (amino acids, lipids) for metabolic and energy consuming processes. Substrates selected for lysosomal degradation by the signal sequence KFERQ can reach their destination also by binding to the chaperone HSC70 and LAMP2A-mediated direct import into the lysosomal lumen (chaperone-mediated autophagy; CMA). The kinase LRRK2 is involved in regulation of CMA and mitophagy, the latter via direct interaction with parkin. Ub: ubiquitin

underlying these symptoms is a progressive preferential loss of ventral dopaminergic (DA) neurons in the pars compacta of the substantia nigra. A histopathological hallmark is the occurrence of intra-cytoplasmic ubiquitin-positive inclusions in surviving neurons known as "Lewy bodies," which are mainly composed of the neuronal protein $\alpha$-synuclein [27]. Approximately $90 \%$ of all PD cases are sporadic with no family history but there are several inherited or de novo mutations that cause PD [28, 29]. For most of them, patient samples have already been used to generate iPSC-derived neurons. Here, we will present the results regarding autophagy and PD chronologically in the background of the inherited mutation. 


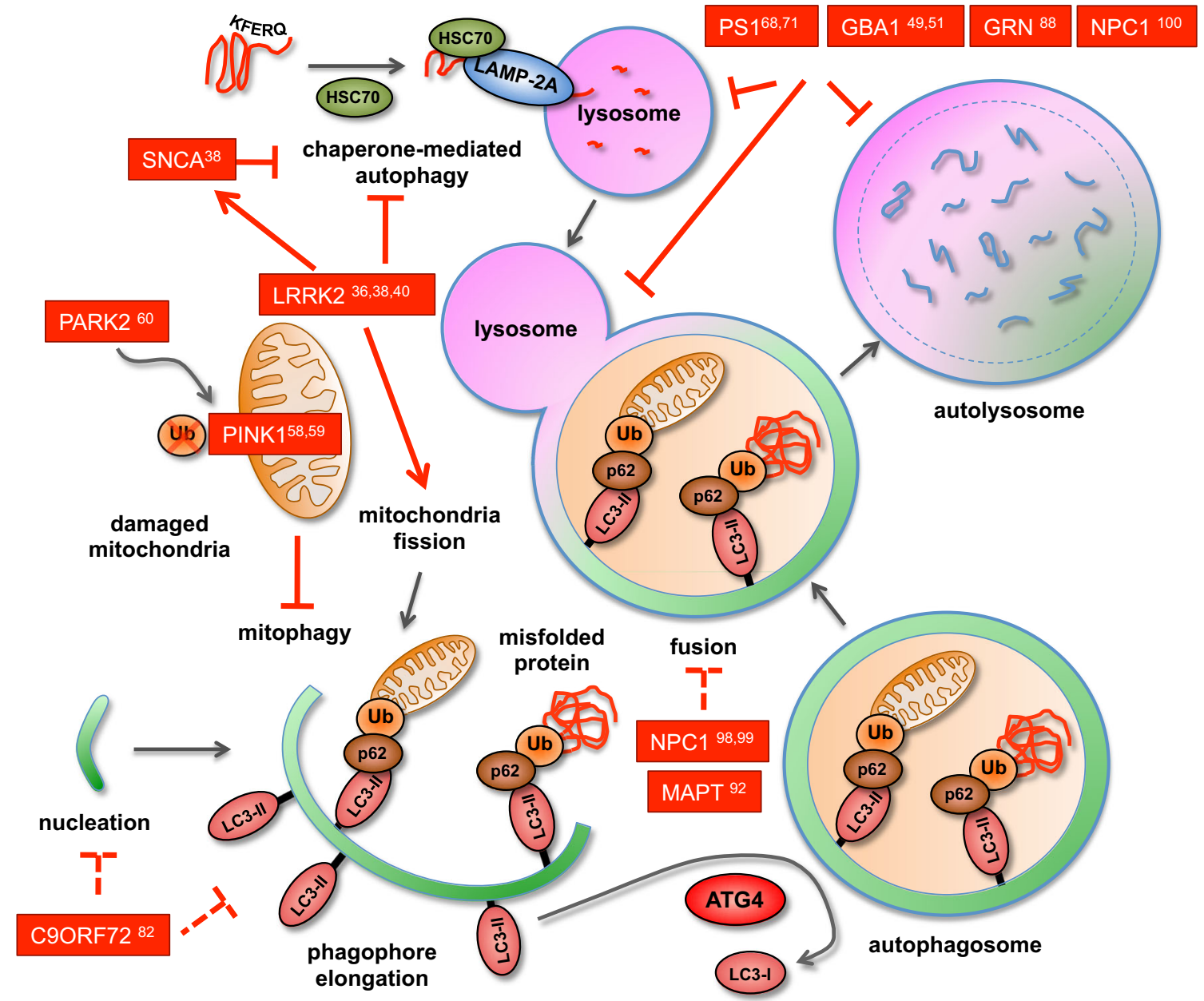

Fig. 3 Modeling disease-associated autophagy in iPSC-derived neurons. Mutations studied in iPSC-derived neurons interfere with the autophagosomal-lysosomal degradation pathway at multiple levels. Mutations in C9ORF72 are associated with impaired phagophore nucleation and/or elongation. Fusion of autophagosomes and lysosomes is compromised by mutations in PS1, GBA1, GRN, and eventually NPC1 and MAPT. PS1, GBA1, and GRN mutations also cause direct defects in lysosomal function, thereby affecting autolysosomes as well as the CMA

\section{LRRK2}

PD-causing mutations in the leucine-rich repeat kinase 2 (LRRK2) are autosomal dominant and manifest as a late-onset PD that is clinically and pathologically indistinguishable from the common idiopathic form [30, 31]. For that reason, LRRK2 mutations represent an interesting target for iPSC-based research into the pathomechanisms underlying PD. While there are over 50 different variants involving various $L R R K 2$ domains in $\mathrm{PD}$ patients, the G2019S mutation is the most prevalent one, being detectable in up to $2 \%$ of sporadic PD cases [32]. Interestingly, an increased kinase activity of LRRK2 has been proposed to mediate the neurotoxic effect of this mutation [33]. pathway. Mutations in parkin and PINK1 selectively impair mitophagy, probably by defective ubiquitination and/or impaired cargo recognition due to mutated binding sites. Mutated LRRK2 induces aberrant fission of mitochondria, thereby interfering with their degradation. LRRK2 mutants are also considered to interfere with CMA by elevating $\alpha$-synuclein (SCNA) levels through mechanisms still to be elucidated. The numbers in superscript refer to the respective publications

In the study from Sanchez-Danes and colleagues [34], iPSCs from 4 LRRK2 $2^{G 2019 S} \mathrm{PD}$ patients, 7 patients with sporadic (non$\mathrm{LRRK}^{\mathrm{G} 2019 \mathrm{~S}}$-related) PD, and 4 healthy control donors were generated. The differentiation into midbrain dopamine (DA) neurons was achieved by overexpression of LMX1A in a 30-day protocol [35], and no significant difference in the yield of neurons was detected, although the fraction of DA neurons was only 9-29\%. Analysis of LC3 in the neuronal cultures by immunoblot showed increased LC3-II levels in PD samples compared to controls, and inhibition of autophagosome-lysosome fusion [20] revealed an impairment of autophagic flux in all PD lines. In addition, electron microscopy (EM) showed accumulation of lipid droplets as well as more autophagosomes compared to 
autophagolysosomes in PD lines, indicative for a defect in autophagic flux through inhibited fusion of autophagosomes with lysosomes.

Su and Qi found that $L R R K 2^{G 2019 S}$ DA neurons exhibit excessive autophagic and lysosomal activity, and mitochondrial dysfunction compared to control DA neurons could be detected at day 30 of differentiation in a protocol based on patterning cues for the ventral midbrain [36]. Interestingly, these phenotypes could be partially reverted by inhibition of mitochondrial fission, pointing to a highly intertwined functional crosstalk between mitochondrial function and autophagy.

Orenstein and colleagues analyzed whether chaperonemediated autophagy (CMA) in LRRK2 $2^{G 2019 S}$ DA neurons is compromised by the interaction of $\alpha$-synuclein with lysosomeassociated membrane protein type 2A (LAMP-2A), the essential component for CMA $[10,37]$. They found elevated $\alpha$-synuclein levels in 30-day-old DA neurons from two LRRK2 $2^{G 2019 S}$ lines compared to two controls and reported a dramatically increased co-localization of $\alpha$-synuclein with LAMP-2A [38]. As $\alpha$ synuclein is considered a substrate of CMA by shuttling through the lysosomal channel protein LAMP-2A into the lysosome, these findings suggest impaired activity of the CMA pathway in this experimental system [38]. Interestingly, the increase in the number of $\alpha$-synuclein ${ }^{+}$DA neurons between day 30 and day 75 in culture could be further increased by knockdown of LAMP-2A.

Reinhardt and colleagues generated isogenic $L R R K 2^{G 2019 S}$ iPSCs from a healthy control line and compared both lines with respect to their LC3-II flux. In this system, a reduced autophagic flux could be detected in the engineered PD line under starvation conditions [39].

Very recently, light was shed on the mechanism how the LRRK2 ${ }^{\mathrm{G} 2019}$ mutation affects the turnover of damaged mitochondria [40]. Hsieh et al. could show that in $L R R K 2^{G 2019}$ iPSC-derived DA neurons, the mitochondrial protein Miro persisted longer on the outer membrane of mitochondria after treatment with the complex III inhibitor antimycin A than on control DA neurons. This was accompanied by delayed recruitment of LC3 and the autophagy receptor optineurin to damaged mitochondria, further arguing for an impairment of mitophagy. In addition, a failure in LC3 recruitment and a delayed turnover of damaged mitochondria could be detected in DA neurons of two sporadic PD lines, thereby implicating a general role of impaired mitophagy in PD.

Ohta et al. investigated another PD-causing LRRK2 mutation, I2020T, located in the LRRK2 kinase domain, using iPSCderived neurons [41]. They discovered slightly increased levels of p62/SQSTM1, a generic autophagy substrate [42], and elevated levels of LC3-II in LRRK2 $2^{\mathrm{I2020T}}$ neuronal cultures compared to controls.
Taken together, the data from PD iPSC models relating to autophagy and LRRK2 mutations point to a model where defective autophagosome-lysosome fusion and delayed turnover of damaged mitochondria might conspire with impaired CMA, thus favoring $\alpha$-synuclein accumulation, increased sensitivity to oxidative stress, and eventually demise of DA neurons.

\section{GBA1}

In recent years, heterozygous mutations in the $\beta$ glucocerebrosidase $(G B A 1)$ gene, which encodes the lysosomal enzyme B-glucocerebrosidase (GCase), have been associated with a higher risk of developing PD, thereby challenging the role of $L R R K 2$ mutations as most common monogenic risk factors for PD [43-45]. GCase is a lysosomal enzyme that hydrolyzes glucosylceramide (Glc-Cer) to ceramide and glucose. Homozygous mutations of GBAl are causing Gaucher's disease (GD), the most prevalent lysosomal storage disorder [46]. GD patients have a 20 -fold increased lifetime risk for developing PD [47]; for heterozygous $G B A 1$ carriers, the lifetime risk is still five times higher than in the general population [43]. Considering these numbers and the fact that $G B A 1$ mutations are also associated with Lewy body dementia [48], understanding the downstream disease mechanisms resulting from these mutations is of great importance.

Exploiting the reprogramming technology, Schöndorf and colleagues generated two control iPSC lines, four GBA1 PD lines, and two GD lines, and even genetically corrected two of the GBA1 PD lines [49]. In both GBA1 PD and GD, there was an accumulation of LAMP1, a lysosomal marker, in DA neurons at day 65 , which was reverted to control levels in gene-corrected cells. In addition, LC3 and LAMP1 co-localized less in GBA1 mutant DA neurons, and LC3-II levels where elevated compared to control and gene-corrected cells. Assessment of autophagic flux revealed impairment of autophagosome-lysosome fusion in GBA1 DA cultures that was not present in control cells and reduced in gene-corrected cells. The authors also reported dysregulated calcium signaling (a mechanism which may contribute to autophagy impairment [50]) and elevated $\alpha$-synuclein as well as Glc-Cer levels that conform to the histopathological phenotype in patient brains.

More recently, Fernandes et al. made use of three control and three unrelated GBA1 PD iPSC lines to generate DA neurons and analyzed them at day 31-35. Their data revealed elevated levels of LC3-II, p62, LAMP1, LAMP-2A, and beclin-1 in GBA1 PD DA neurons compared to controls. These observations strongly suggest that autophagosomal-lysosomal turnover is impaired in the mutant lines, although autophagic flux was not directly investigated [51]. Strikingly, EM analysis confirmed an increased number of autophagosomes and lysosomes with undigested cargo. Taken together, the experimental evidence emerging from 
these studies points to an impaired autophagic flux as a contributing factor for GBAl-linked PD.

\section{PINK1 and parkin/PARK2}

PTEN-induced putative kinase 1 (PINK1) and parkin (PARK2) exert essential functions in mitochondrial homeostasis and quality control [52-54]. Recessively inherited mutations in both genes are related to PD [55, 56]. Parkin functions as an E3 ubiquitin ligase that ubiquitinates PINK1 on the outer membrane of damaged and aged mitochondria $[54,55]$ to enable their removal by p62-mediated autophagy, a process referred to as "mitophagy" [57].

For the investigation of PINK1, Seibler et al. generated one iPSC line each from one PINK1 PD patient and one healthy family member, derived DA neurons and, at day 60 of differentiation, analyzed the recruitment of parkin to mitochondria upon treatment with the potassium carrier and antibiotic valinomycin [58]. They observed that PINK1 PD DA neurons - in contrast to controls - showed no recruitment of parkin to mitochondria. Furthermore, no reduction of mitochondrial DNA, an indicator of damaged mitochondria removal, could be detected. Both defects, lack of parkin recruitment and impaired mitochondria removal, were restored by overexpression of wild-type PINK1. This phenotype of defective parkin recruitment to mitochondria in PINK1 PD DA neurons upon valinomycin treatment could be recapitulated by Rakovic and colleagues using one PINK1 PD iPSC line and one control [59].

To investigate the effect of parkin mutations, Shatoulki et al. used 4-week-old DA neurons derived from four $P A R K 2$ PD patients, one healthy control along with heteroand homozygous PARK2 knockout iPSC lines [60]. Although parkin localization or direct mitophagy was not assessed, all parkin-deficient lines, hetero- and homozygous, generated less DA neurons, with PARK2 patient neurons containing less mitochondrial mass than control neurons. Collectively, these data suggest that impairment of mitochondria turnover is a contributing factor in PINK1/parkin-related PD.

\section{Alzheimer's disease}

Alzheimer's disease (AD) is the most frequent form of dementia and the most common neurodegenerative disorder. AD is clinically characterized by progressive loss of memory and neuropathologically by the presence of amyloid plaques and neurofibrillary tangles [61]. Intriguingly, functional abnormalities of autophagosomes and lysosomes were found to precede these paradigmatic pathological changes in AD brains [62]. Interestingly, presenilin 1
(PS1), the most commonly affected gene in early onset familial AD [63], is essential for lysosomal and autophagy function [64] with AD-linked PS1 mutations impairing these pathways [65]. In addition, elevated levels of acid sphingomyelinase (ASM) are associated with AD [66], and sphingomyelin metabolism is regulated by presenilins [67]. Alterations of ASM activity could therefore be a downstream effect of presenilin mutations in AD.

Addressing this relationship, Lee and colleagues reprogrammed cells from one PS1 AD patient and one control subject to iPSC and assessed the ASM levels in the clonally derived PS1 lines and their neuronal derivatives [68]. In the PS1 iPSC line with the highest ASM levels, LC3-II and p62 levels in iPSC-derived neurons were elevated whereas the levels of LAMP1 and the basic helix-loop-helix transcription factor EB (TFEB), a transcriptional master regulator of autophagy $[69,70]$, were decreased. EM analysis of iPSC-derived neurons revealed an accumulation of autophagosomes in PS1 AD neurons. Knockdown of ASM by siRNA in PS1 AD neurons normalized the levels of LC3-II, p62, LAMP1, and TFEB comparable to control neurons, reduced autophagosome number detected by EM, and further partially restored the impaired expression of TFEB target genes such as cathepsin B. These findings argue for a defect in autophagosomal-lysosomal fusion mediated by ASM activity in PS1 AD neurons.

Using two PS1 AD and two control iPSC lines, Reddy et al. found that PS1 AD neurons exhibit decreased nuclear calcium signaling compared to control neurons [71]. Moreover, knockdown of PS1, cAMP responsive element binding protein (CREB) or calcium/calmodulin dependent protein kinase IV (CaMKIV) in control neurons resulted in decreased expression of sestrin2, LC3 and p62. Noteworthy, PS1 overexpression could not rescue the observed gene expression alterations in the CREB/ CaMKIV knock-down setting, thus placing dysregulated nuclear calcium signaling downstream of the PS1 mutation. Upon application of a calcium ionophore increasing the cytosolic calcium level, LC3-GFP punctae were increased in PS1 AD neurons; in the same setting, PS1 depleted neurons showed a calcium dependent increase of sestrin 2 with the decreased autophagic flux being reestablished. Taken together, these findings suggest that PS1 AD iPSC-derived neurons show a deficiency in autophagic flux, which is probably mediated by altered nuclear calcium signaling as well as altered sphingomyelin metabolism and subsequent downregulation of TFEB and its target genes.

\section{Frontotemporal dementia/amyotrophic lateral sclerosis}

The neurodegenerative disorder manifesting clinically as frontotemporal dementia (FTD) is genetically a pleiotropic group of sporadic cases and identified different mutations [72, 73]. Some of the mutations linked to FTD also manifest as 
amyotrophic lateral sclerosis (ALS) [74]. FTD is characterized by focal but progressive neuronal atrophy in the frontal and temporal cortices as well as astrogliosis, inflammation, and prominent intracellular protein inclusions, mostly positive for ubiquitin, tau protein, p62, and TAR DNA-binding protein 43 (TDP43) [75, 76]. Given the heterogeneity of FTD, this section will focus on distinct genetic changes that have been addressed using iPSC models.

\section{C9ORF72}

The hexanucleotide repeat expansion GGGGCC in the noncoding region of the C9ORF72 gene is the most common known pathogenic mutation underlying FTD and ALS [77-79]. A number of different pathogenic mechanisms have been proposed, including C9ORF72 haploinsufficiency, RNA toxicity, and repeat-associated non-ATG (RAN) translation of neurotoxic dipeptides [80, 81].

In their search for neuropathological phenotypes in C9ORF72 iPSC-derived neurons from two patients compared to one control, Almeida and colleagues stressed the neuronal cultures around day 35 with the lysosomal inhibitor chloroquine and the autophagosome formation inhibitor 3-methyladenine [82]. C9ORF72 neuronal cultures displayed a higher vulnerability and increased cell death upon inhibitor exposure than control cultures and showed increased levels of p62, although autophagic flux was not assessed. These findings could point to a contribution of autophagic impairment to the pathogenesis of C9ORF72-related FTD and also ALS. Interestingly, a recent study established a link between loss of C9ORF72 and impairment of autophagy, as C9ORF72 is involved in regulating autophagy induction via forming a complex with SMCR8 and WDR41, two proteins involved in the early steps of autophagosome formation [83].

\section{$G R N$}

Progranulin (PGRN) is a secreted glycoprotein involved in cell survival, inflammation, and neuroprotection $[84,85]$. In the vast majority of cases mutations in the GRN gene encoding PGRN result in haploinsufficiency and decreased expression of the protein. The complete loss of PGRN is one genetic cause for earlyonset neuronal ceroid lipofuscinosis, a pleiotropic multiform lysosomal storage disorder, implicating a role in lysosome homeostasis [86].

To treat the haploinsufficiency of PGRN, Holler et al. screened for potential inducers of PGRN expression and went on to validate their hit, the autophagy inducer trehalose [87], in 25-day-old iPSC-derived motor neurons generated from one control and one patient-derived GRN line [88]. Application of trehalose elevated PGRN and LC3-II in GRN neurons, but there was no increase of LC3-II in control neurons. Unfortunately, autophagic flux was not assessed in this study, which will be required to determine whether trehalose represents a therapeutic option for treating PGRN- associated FTD.

\section{MAPT}

The tau protein, encoded by the MAPT gene, is ubiquitously expressed in the brain with a predominant localization in axons, where it is involved in microtubule polymerization and organelle transport [89]. There are many different mutations in MAPT linked to FTD [87], including the A152T mutation [90, 91].

Characterizing their iPSC-based FTD model comprising two patient lines, two control lines and also a MAPT knockout line, Silva et al. discovered elevated levels of LC3-II, p62, LAMP1, LAMP-2A, ATG12-5 and also an accumulation of ubiquitinated proteins in 35-day-old cortical neuronal cultures derived from MAPT ${ }^{A 152 T}$ iPSCs [92]. Interestingly, the detected susceptibility to rotenone, NMDA or amyloid- $\beta$ toxicity as well as elevated levels of tau and phospho-tau could be attenuated by treatment with rapamycin. Although autophagic flux was not directly investigated, the observed reduction of tau protein, a known substrate of autophagy [93], could suggest that the effect is elicited by an increase in autophagic flux, thereby depicting rapamycin as potential candidate for the treatment of $M A P T$-linked FTD.

\section{Niemann-Pick type $\mathbf{C}$ disease}

Like GD, Niemann-Pick type C disease (NPC) is an inherited autosomal recessive lysosomal storage disorder where $>95 \%$ of cases are caused by loss-of-function mutations in the $\mathrm{NPCl}$ gene, leading to severe neurodegeneration and liver dysfunction [94, 95]. The result of lost NPC1 function is impaired cholesterol homeostasis that mediates damage in liver and brain [96]. Interestingly, autophagy is involved in lipid metabolism [96] and, conversely, cellular lipid content affects autophagosomal membrane turnover [97]. Therefore, alterations in lipid composition are likely to affect the autophagy pathway.

As NPC is a recessive disorder, Maetzel et al. reprogrammed four NPC patients, one heterozygous healthy control and one homozygous control, and even genetically corrected one NPC line to a homozygous wild type genotype [98]. Neuronal cultures from NPC patients showed elevated LC3-II and p62 levels compared to control cells and the isogenic control at day 28 , and the autophagic flux in NPC neurons was reduced. A compound screen for normalization of p62 levels revealed carbamazepine as a potential drug for NPC treatment.

Using one NPC iPSC line and one healthy control, Lee and colleagues detected also elevated LC3-II and p62 levels in NPC neurons compared to control cultures. In addition, they assessed 
autophagosome-lysosome turnover by electron microscopy and a fluorescence mCherry-eGFP-LC3 reporter assay (where eGFP fluorescence is quenched in the acidic lysosomal environment, thereby labeling fused autolysosomes purely red [99]). Both EM and LC3 reporter analysis revealed an accumulation of autophagosomes in NPC neurons compared to control cells. The detected autophagosomal-lysosomal turnover impairment could be rescued by application of vascular endothelial growth factor (VEGF).

The third study that reported an elevation of LC3-II and p62 in NPC iPSC-derived neural cells compared to control cultures was performed by Soga et al. using two NPC iPSC lines (two clones each) and two control iPSC lines [100], though only neural progenitor cells were analyzed. Nevertheless, treatment of NPC neural progenitors with 2-hydroxypropyl-c-cyclodextrin, a substance that induces release of cholesterol from late endosomes and lysosomes [98], decreased LC3-II and p62 levels without effecting viability. All three NPC iPSC-based studies presented here point to a reduced autophagic flux as pathogenic mechanism underlying NPC. They further exemplify the potential usefulness for iPSC-derived neurons for validating drug candidates that may restore autophagic flux.

\section{Appropriate controls and cell types matter}

A closer look at studies with different patient lines reveals that a disease-specific phenotype can vary markedly amongst iPSC lines derived from different subjects and even between clones generated from the same subject, although there might still by a significant difference to control lines [68]. To avoid false conclusions in either direction that are solely based on genetic variability and not disease-related, the generation of isogenic iPSC pairs is strongly recommended whenever possible. Generating isogenic iPSC lines is greatly assisted by emerging genome editing techniques such as the CRISPR/Cas9 system [101].

One of the major puzzling questions associated with the pathogenesis of neurodegenerative diseases is why ubiquitously expressed mutant proteins exert their main detrimental effects specifically in neurons and even in defined neuronal subtypes. This basic observation calls for model systems which enable pathogenetic studies in distinct human neuronal subtypes, a scenario which has become palpable with the advent of cell reprogramming and recent progress in the in vitro differentiation of iPSC towards a number of neural sublineages. Indeed, some of the phenotypes observed in the PD-related iPSC studies discussed in this review were reported to be visible only when DA neurons were assessed $[38,51,58]$. Along the same line, in a recently reported ALS iPSC study, a neurofilament phenotype could only been delineated in motoneurons but not in interneurons [102]. Thus, choosing the right differentiation protocol and neuronal subtype for each disease can be of major importance, although it might be possible to discover disease-related alterations in other neural subtypes as well.

\section{Flux or no flux}

Frequently, controversies in the field of autophagy arise from the different interpretation of observed changes as either activation or inhibition of autophagy. This phenomenon underscores the necessity to differentiate between the induction of the autophagic process and the concept of autophagic flux [20]. For example, elevated levels of LC3-II can result either from increased induction of autophagic activity (e.g., by inhibition of the mTOR pathway) or by blockade of autophagic flux via impairment of lysosomal degradation [20]. The majority of the studies revisited in this review took this caveat already into consideration, but some results could still faithfully be interpreted the opposite way the authors initially suggested. To avoid such ambiguity, future studies should assess autophagic flux whenever possible, e.g., by introduction of tandem fluorochrome reporter systems for measurement of direct turn-over of autophagy substrates, or by the use of lysosomal inhibitors (such as Bafilomycin A, or the combination Leupeptin/E64) to block the endpoint of degradation. In addition, the investigation of additional parameters such as p62 or BECN1 turnover in addition to analysis of LC3 conversion is recommended. It is important to realize that such studies can still be confounded by, e.g., context-dependent transcriptional (up-) regulation of LC3 and p62, or spontaneous aggregation of reporter fusion proteins such as p62-GFP [103, 104].

\section{Outlook}

While autophagy and iPS cell-based disease modeling have both become key topics in neurodegeneration research (see summary in Table 1), there is still a lot of room for synergyzing these two fields. The studies presented here show that iPSC models can be used successfully to identify autophagy-related phenotypes associated with different neurodegenerative diseases. This approach is not only suitable for the detection of new autophagy-related pathomechanisms but also for corroborating or dismissing presumptive diseaserelated disturbances in autophagy described in other, less authentic model systems.

Of particular interest will be the further investigation of iPSC models of diseases where a pathologically aggregating protein is a known autophagy substrate such as, e.g., in the polyglutamine (polyQ) disorders Spinal and Bulbar Muscular Atrophy (SBMA) [105], Huntington's Disease (HD) [106], and Machado-Joseph Disease (MJD) [107]. Experiments in 
Table 1 iPSC-based models of neurodegenerative diseases with focus on the autophagy-lysosomal system

\begin{tabular}{|c|c|c|c|c|c|}
\hline Disease & $\begin{array}{l}\text { Disease-linked } \\
\text { gene }\end{array}$ & Cell type analyzed & $\begin{array}{l}\text { No. of patient/control } \\
\text { lines }\end{array}$ & Proposed autophagy-related pathophenotype & Reference \\
\hline \multirow[t]{11}{*}{$\mathrm{PD}$} & LRRK2 (G2019S) & Midbrain DA neurons & $11 / 4^{\mathrm{a}}$ & Defective autophagosome clearance & {$[35]$} \\
\hline & LRRK2 (G2019S) & DA neurons & $1 / 1$ & $\begin{array}{l}\text { Excessive mitochondrial fission } \rightarrow \text { exacerbated } \\
\text { autophagy induction }\end{array}$ & {$[36]$} \\
\hline & LRRK2 (G2019S) & DA neurons & $1 / 2$ & LRRK2 ${ }^{\mathrm{G} 2019 \mathrm{~S}}$-dependent impairment of CMA & {$[38]$} \\
\hline & LRRK2 (G2019S) & Neurons & $1 / 1^{\mathrm{b}}$ & Autophagic defect under starvation conditions & {$[39]$} \\
\hline & LRRK2 (G2019S) & DA neurons & $3 / 3^{\mathrm{c}}$ & Impaired mitochondria turn-over by Miro stabilization & {$[40]$} \\
\hline & LRRK2 (I2020T) & Neurons & $2 / 2$ & Decreased autophagic flux & {$[41]$} \\
\hline & GBA1 & DA neurons & $4 / 4^{\mathrm{d}}$ & Impaired autophagosome-lysosome fusion & [49] \\
\hline & GBA1 & DA neurons & $3 / 3$ & Impaired lysosomal degradation & {$[51]$} \\
\hline & PINK1 & DA neurons & $1 / 1$ & Defective Parkin-mediated mitophagy & {$[58]$} \\
\hline & PINK1 & DA neurons & $1 / 1$ & Defective Parkin-mediated mitophagy & {$[59]$} \\
\hline & PARK2 & DA neurons & $5 / 1^{\mathrm{e}}$ & Defective mitophagy & {$[60]$} \\
\hline \multirow[t]{2}{*}{$\mathrm{AD}$} & PS1 & iPSCs and neurons & $1 / 1$ & Lysosomal depletion and defective autophagic degradation & {$[68]$} \\
\hline & PS1 & Neurons & $2 / 2$ & Impaired autophagy & [71] \\
\hline \multirow[t]{2}{*}{ FTD } & GRN & Motor neurons & $1 / 1$ & Impaired autophagosomal-lysosomal turnover & {$[88]$} \\
\hline & MAPT & Cortical neurons & $3 / 2^{\mathrm{f}}$ & Impaired autophagosomal-lysosomal turnover & {$[92]$} \\
\hline ALS \& FTD & C9ORF72 ${ }^{g}$ & Neurons & $2 / 1$ & Impaired autophagy & {$[82]$} \\
\hline \multirow[t]{3}{*}{ NPC } & NPC1 & Neurons & $4 / 3^{\mathrm{h}}$ & Impaired autophagic flux & [98] \\
\hline & $\mathrm{NPC1}$ & Neurons & $1 / 1$ & Impaired autophagosomal-lysosomal turnover & [99] \\
\hline & $\mathrm{NPCl}$ & Neural progenitors & $2 / 2$ & Impaired autophagy & {$[100]$} \\
\hline \multicolumn{6}{|c|}{${ }^{\mathrm{a}} 7$ sporadic $\mathrm{PD}+4$ LRRK2-mut } \\
\hline \multicolumn{6}{|c|}{${ }^{\mathrm{b}}$ Engineered/parental } \\
\hline \multicolumn{6}{|c|}{${ }^{\mathrm{c}} 3$ controls ( 2 healthy +1 gene corrected) } \\
\hline \multicolumn{6}{|c|}{$\mathrm{d} 4$ controls $(2$ healthy +2 gene corrected $)$} \\
\hline \multicolumn{6}{|c|}{${ }^{\mathrm{e}} 4$ iPSC disease lines +1 PARK2- knock out line/1 control } \\
\hline \multicolumn{6}{|c|}{${ }^{\mathrm{f}} 2$ iPSC disease lines +1 MAPT_ - knock out line $/ 1$ control } \\
\hline \multicolumn{6}{|c|}{${ }^{\mathrm{g}}$ C9ORF72 (polyGGGGCC) } \\
\hline${ }^{\mathrm{h}} 3$ controls ( & 2 healthy +1 gene & rected) & & & \\
\hline
\end{tabular}

this direction are bound to provide more insight into the pathogenic role of autophagy as exemplified by a recent study showing impairment of TFEB-mediated autophagy already in iPSC-derived neural precursors derived from SBMA patients [105]. Such an early manifestation of a phenotype raises the question whether autophagy impairment exerts its pathogenic role already during development.

Further key questions to be addressed are whether and to what extent autophagy is differently regulated in neuronal subtypes and why general modulation of autophagy elicits specific effects in individual cellular subtypes [108, 109]. IPSC-derived neurons could also be used to gain insight into the role of autophagy during age-associated progression of a neurodegenerative phenotype [110] and potentially open new avenues towards slowing down the aging process by precise modulation of autophagic pathways [25].

Future studies may also address a potential disease-related role of autophagy in glial cells. While autophagy appears to be particularly relevant in neurons due to the unique biology of this cell type (postmitotic state, high energy demands, extreme life span), there is growing evidence for specialized functions of autophagy pathways in glial cells (reviewed in [111]). Examples include a contribution to myelination in oligodendrocytes, a possible role in synaptic pruning in astrocytes, and autophagy-mediated cell death in microglia [111]. Furthermore, there is evidence that oligodendroglial $\alpha$ synuclein inclusions in multiple system atrophy (MSA) patients are co-localizing with LC3, p62 and ubiquitin [112, 113]. It will be interesting to decipher the role of autophagy in the generation of these glial inclusions using iPSC-derived oligodendrocytes and whether a dysregulation of autophagy contributes to the pathogenesis of MSA and other neurological disorders.

Taken together, while both, cell reprogramming and autophagy, have already been subject of Nobel Prizes, the amalgamation of both research lines towards understanding and treating neurodegenerative disorders has just begun. 
Textbox 1. Definition of autophagy-related terms.

\begin{tabular}{|c|c|}
\hline term & definition / comment \\
\hline ATGs & $\begin{array}{l}\text { Abbreviation for 'autophagy related genes', i.e. evolutionary } \\
\text { conserved components of the protein machinery that are involved } \\
\text { in selective and non-selective modes of autophagy. }\end{array}$ \\
\hline $\begin{array}{l}\text { autophagic flux } \\
\text { (or , autophagic flow') }\end{array}$ & $\begin{array}{l}\text { Term describing the entire turnover of material through the } \\
\text { autophagic system, from sequestration of cargo to degradation in } \\
\text { the lysosomes/vacuoles and recycling of molecules. The } \\
\text { autophagic ,flux' must be distinguished from 'induction'of the } \\
\text { system (by engagement of upstream signaling events, e.g. inhibition of } \\
\text { the TOR pathway). Common methods to determine autophagic flux } \\
\text { include the use of tandem-fluorochrome assays and the analysis } \\
\text { of cargo turnover (e.g. LC3-II, p62) in combination with blockade } \\
\text { of lysosomal degradation (e.g. by E64/Leupeptin, chloroquine or } \\
\text { bafilomycin A1). }\end{array}$ \\
\hline autophagolysosomes & $\begin{array}{l}\text { A membrane-bound degradative compartment formed by the } \\
\text { fusion of an autophagosome with the lysosomal compartment, } \\
\text { involving activity of the macroautophagic machinery. }\end{array}$ \\
\hline autophagosomes & $\begin{array}{l}\text { A non-degradative cytosolic compartment characterized by a } \\
\text { double membrane that is often decorated with LC3-II (or its } \\
\text { orthologues, e.g. Atg8). Autophagosomes sequester cytosolic } \\
\text { components (,cargo') and mediate their lysosomal degradation by } \\
\text { transport towards and fusion with lysosomes. }\end{array}$ \\
\hline autophagy & $\begin{array}{l}\text { Umbrella term describing the delivery of cytoplasmic material } \\
\text { ('cargo') to lysosomes/vacuoles, resulting in degradation of the } \\
\text { cargo and recycling of the respective molecular building blocks. }\end{array}$ \\
\hline autophagy induction & $\begin{array}{l}\text { Term describing conditions that trigger (increased) activation of } \\
\text { the autophagic system by engagement of upstream signaling } \\
\text { events. Typical inducers of autophagy are nutrient deprivation, } \\
\text { TOR inhibition (e.g. by rapamycin, torin1), redox stress, cytosolic } \\
\text { pathogens and various pleiotropic compounds (e.g. trehalose, } \\
\text { spermidine). Experimental assays to monitor autophagy induction } \\
\text { include detection of LC3 processing (LC3-I } \rightarrow \text { LC3-II) by Western } \\
\text { blotting and quantification of autophagosome formation (e.g. by } \\
\text { immunostaining of LC3 or ectopic expression of GFP-LC3 or } \\
\text { variants thereof). }\end{array}$ \\
\hline autophagy receptors & $\begin{array}{l}\text { A group of proteins that are capable to target specific cargo for } \\
\text { selective autophagic degradation by physically linking cargo (or } \\
\text { molecular tags on its cytosolic surface) to LC3 family members. } \\
\text { Typically, autophagy receptors (such as p62/SQSTM1, NBR1, } \\
\text { OPTN, NDP52) themselves become degraded and thus can } \\
\text { serve as markers for autophagic activity. }\end{array}$ \\
\hline $\begin{array}{l}\text { chaperone-assisted } \\
\text { selective autophagy } \\
\text { (CASA) }\end{array}$ & $\begin{array}{l}\text { An autophagic process that utilizes the co-chaperone BAG3 (the } \\
\text { mammalian orthologue of starvin in Drosophila) to facilitate the } \\
\text { degradation of aggregated substrates. While ubiquitination of the } \\
\text { cargo is a requirement for CASA, this pathway does not rely on } \\
\text { the presence of the KFERQ motif in the cargo protein sequence } \\
\text { (see CMA). }\end{array}$ \\
\hline $\begin{array}{l}\text { chaperone -mediated } \\
\text { autophagy (CMA) }\end{array}$ & $\begin{array}{l}\text { An autophagic process in mammalian cells by which proteins } \\
\text { containing a particular pentapeptide motif (KFERQ or its variants) } \\
\text { are selectively translocated into the lysosomal lumen for } \\
\text { degradation. There cognition and recruitment of cargo is mediated } \\
\text { by the chaperone HSC70, while the translocation process } \\
\text { requires the lysosomal membrane protein LAMP-2A. }\end{array}$ \\
\hline LC3 & $\begin{array}{l}\text { Abbreviation for 'microtubule-associated protein } 1 \text { light chain 3', } \\
\text { an evolutionary conserved family of proteins that are pivotally } \\
\text { involved in autophagosome formation and fusion events. During } \\
\text { autophagy induction, the cytosolic LC3 (then called LC -I) is } \\
\text { proteolytically cleaved and fused to phosphatidylethanolamine } \\
\text { (PE) which enables its insertion into the growing autophagosomal } \\
\text { membrane. The membrane-anchored PE-conjugated form of LC3 } \\
\text { is termed LC3-II. During autophagy execution, LC3 is removed } \\
\text { from the cytosolic face of the autophagosome but remains inside } \\
\text { the vesicle and thus is degraded along with the cargo within the } \\
\text { lysosomal compartment. While the conversion of LC3-I to LC3-II } \\
\text { is often used to analyze autophagy induction and flux, it is } \\
\text { important to note that the result of this conversion is higly } \\
\text { dependent on the cell type, the treatment and the experimental } \\
\text { context. Blockade of lysosomal degradation during a treatment } \\
\text { period is recommended in order to stabilize LC3-II and thus to use the } \\
\text { LC3-II/I ratio as a measure of autophagic flux. }\end{array}$ \\
\hline macroautophagy & $\begin{array}{l}\text { The autophagic sequestration of cytoplasmic cargo into a double- } \\
\text { membrane bound vesicle (, autophagosome') followed by } \\
\text { degradation by the lysosomal/vacuolar system. Importantly, some } \\
\text { proteins and organelles may be selectively degraded via } \\
\text { macroautophagy while other cytosolic components (e.g. } \\
\text { cytoskeletal elements) are selectively excluded from degradation. }\end{array}$ \\
\hline microautophagy & $\begin{array}{l}\text { An autophagic process involving direct uptake of cytosolic } \\
\text { components, inclusions and organelles (e.g. ribosomes) at the } \\
\text { lysosome/vacuole by invagination of the sequestering organelle } \\
\text { membrane. }\end{array}$ \\
\hline mitophagy & $\begin{array}{l}\text { A prominent type of selective autophagy, involving autophagic } \\
\text { sequestration and degradation of mitochondria. Mitophagy is } \\
\text { induced by organelle aging or damage accumulation (e.g. due to } \\
\text { membrane depolarization). In mammalian cells, at least two } \\
\text { mitophagy pathways exist, i.e. the PINK1/parkin and the NIX } \\
\text { pathway. }\end{array}$ \\
\hline
\end{tabular}

\begin{tabular}{|l|l|}
\hline selective autophagy & $\begin{array}{l}\text { In contrast to non-selective ('bulk') autophagy, the selective types } \\
\text { of autophagy target specific cargo for degr adation (e .g. } \\
\text { mitochondria by mitophagy, bacteria by xenophagy, peroxisomes } \\
\text { by pexophagy). Specificity is often regulated by involvement of } \\
\text { autophagy receptors that specifically recognize molecular tags on } \\
\text { cargo and physically link these entities to LC3 family members, } \\
\text { thus facilitating engulfment by the growing autophagosome. }\end{array}$ \\
\hline starvation & $\begin{array}{l}\text { In the context of autophagy, this term often describes cultivation } \\
\text { conditions that trigger autophagy activation, i.e. by omitting } \\
\text { serum, selective growth factors, nutrients, nitrogen sources or } \\
\text { amino acids. As different forms of starvation can induce distinct } \\
\text { responses, it is important to define the exact type of starvation } \\
\text { applied in a given experimental setting. }\end{array}$ \\
\hline $\begin{array}{l}\text { tandem fluorochrome } \\
\text { assay }\end{array}$ & $\begin{array}{l}\text { A methodology that is commonly used to analyze autophagic flux, } \\
\text { based on ectopic expression of a red fluorescent protein variant } \\
\text { (e.g. RFP) directly fused in frame with a green fluorescent protein } \\
\text { (e.g. GFP) and some localisation signal or target protein (e.g. } \\
\text { LC3). The mode of action of these tandem fluorochrome } \\
\text { biosensors is based on the differential stability of the two } \\
\text { fluorochromes under varying pH conditions (i.e. cytosolic vs } \\
\text { lysosomal). Accumulation of red fluorescent signals over a double } \\
\text { positive (yellow) background is indicative for lysosomal turnover } \\
\text { of the fusion protein. }\end{array}$ \\
\hline
\end{tabular}

Acknowledgments Work at the Institute of Reconstructive Neurobiology and LIFE \& BRAIN GmbH has been supported by the EU (FP7- HEALTH-F4-2013-602278-Neurostemcellrepair; FP7HEALTH-F5-2010-266753-SCR\&Tox, COLIPA, IMI-115582-EBiSC, Horizon2020-667301-COSYN, IMI2-115975-2-ADAPTED, IMI2115976-2-PHAGO), BMBF (grants 13N11830-LANDCEM, 01EK1603A-Neuro2D3, 01EK1603B-Neuro2D3 and a grant within the framework of the e:Med research and a funding concept 01ZX1314AIntegraMent), the North Rhine Westphalian Ministry of Innovation, Science and Research Programmes (grants 005-1403-0102, 005-14030106 StemCellFactory II), the North Rhine Westphalian Programme LifeSciences.NRW, European Regional Development Fund (EFRE0800407, EFRE-0800408 NeuRoWeg), the Stem Cell Network North Rhine Westphalia and BONFOR.

Open Access This article is distributed under the terms of the Creative Commons Attribution 4.0 International License (http:// creativecommons.org/licenses/by/4.0/), which permits unrestricted use, distribution, and reproduction in any medium, provided you give appropriate credit to the original author(s) and the source, provide a link to the Creative Commons license, and indicate if changes were made.

\section{References}

1. Scudellari M (2016) How iPS cells changed the world. Nature 534:310-312

2. Ohsumi Y (2012) Yoshinori Ohsumi: autophagy from beginning to end. Interview by Caitlin Sedwick. J Cell Biol 197(2):164-165

3. Takahashi K, Yamanaka S (2006) Induction of pluripotent stem cells from mouse embryonic and adult fibroblast cultures by defined factors. Cell 126:663-676

4. Takahashi K, Tanabe K, Ohnuki M, Narita M, Ichisaka T, Tomoda K, Yamanaka S (2007) Induction of pluripotent stem cells from adult human fibroblasts by defined factors. Cell 131:861-872

5. Yu J, Vodyanik MA, Smuga-Otto K, Antosiewicz-Bourget J, Frane JL, Tian S, Nie J, Jonsdottir GA, Ruotti V, Stewart R et al (2007) Induced pluripotent stem cell lines derived from human somatic cells. Science 318:1917-1920

6. Tsukada M, Ohsumi Y (1993) Isolation and characterization of autophagy-defective mutants of Saccharomyces cerevisiae. FEBS Lett 333:169-174 
7. de Duve C (1963) Ciba Foundation Symposium: Lysosome. In: De Reuck A, Cameron MP (eds) Little, Brown

8. Ahlberg J, Marzella L, Glaumann H (1982) Uptake and degradation of proteins by isolated rat liver lysosomes. Suggestion of a microautophagic pathway of proteolysis. Lab Investig 47:523532

9. Arndt V, Dick N, Tawo R, Dreiseidler M, Wenzel D, Hesse M, Furst DO, Saftig P, Saint R, Fleischmann BK et al (2010) Chaperone-assisted selective autophagy is essential for muscle maintenance. Curr Biol 20:143-148

10. Cuervo AM, Dice JF (1996) A receptor for the selective uptake and degradation of proteins by lysosomes. Science 273:501-503

11. Dice JF, Terlecky SR, Chiang HL, Olson TS, Isenman LD, ShortRussell SR, Freundlieb S, Terlecky LJ (1990) A selective pathway for degradation of cytosolic proteins by lysosomes. Semin Cell Biol 1:449-455

12. Arstila AU, Trump BF (1968) Studies on cellular autophagocytosis. The formation of autophagic vacuoles in the liver after glucagon administration. Am J Pathol 53:687-733

13. Mizushima N, Noda T, Yoshimori T, Tanaka Y, Ishii T, George MD, Klionsky DJ, Ohsumi M, Ohsumi Y (1998) A protein conjugation system essential for autophagy. Nature 395:395-398

14. Mizushima N, Noda T, Ohsumi Y (1999) Apg16p is required for the function of the Apg12p-Apg5p conjugate in the yeast autophagy pathway. EMBO J 18:3888-3896

15. Kuma A, Mizushima N, Ishihara N, Ohsumi Y (2002) Formation of the approximately 350-kDa Apg12-Apg5.Apg16 multimeric complex, mediated by Apg16 oligomerization, is essential for autophagy in yeast. J Biol Chem 277:18619-18625

16. Mizushima N, Sugita H, Yoshimori T, Ohsumi Y (1998) A new protein conjugation system in human. The counterpart of the yeast Apg12p conjugation system essential for autophagy. J Biol Chem 273:33889-33892

17. Mizushima N, Kuma A, Kobayashi Y, Yamamoto A, Matsubae M, Takao T, Natsume T, Ohsumi Y, Yoshimori T (2003) Mouse Apg16L, a novel WD-repeat protein, targets to the autophagic isolation membrane with the Apg12-Apg5 conjugate. J Cell Sci 116:1679-1688

18. Ichimura Y, Kirisako T, Takao T, Satomi Y, Shimonishi Y, Ishihara N, Mizushima N, Tanida I, Kominami E, Ohsumi M et al (2000) A ubiquitin-like system mediates protein lipidation. Nature 408: 488-492

19. Kabeya Y, Mizushima N, Ueno T, Yamamoto A, Kirisako T, Noda T, Kominami E, Ohsumi Y, Yoshimori T (2000) LC3, a mammalian homologue of yeast Apg8p, is localized in autophagosome membranes after processing. EMBO J 19:5720-5728

20. Mizushima N, Yoshimori T (2007) How to interpret LC3 immunoblotting. Autophagy 3:542-545

21. Hara T, Nakamura K, Matsui M, Yamamoto A, Nakahara Y, Suzuki-Migishima R, Yokoyama M, Mishima K, Saito I, Okano $\mathrm{H}$ et al (2006) Suppression of basal autophagy in neural cells causes neurodegenerative disease in mice. Nature 441:885-889

22. Komatsu M, Waguri S, Chiba T, Murata S, Iwata J, Tanida I, Ueno T, Koike M, Uchiyama Y, Kominami E et al (2006) Loss of autophagy in the central nervous system causes neurodegeneration in mice. Nature 441:880-884

23. Nixon RA (2013) The role of autophagy in neurodegenerative disease. Nat Med 19:983-997

24. Zhong Z, Sanchez-Lopez E, Karin M (2016) Autophagy, inflammation, and immunity: a troika governing cancer and its treatment. Cell 166:288-298

25. Rubinsztein DC, Marino G, Kroemer G (2011) Autophagy and aging. Cell 146:682-695
26. Lees AJ, Hardy J, Revesz T (2009) Parkinson's disease. Lancet 373:2055-2066

27. Schapira AH, Tolosa E (2010) Molecular and clinical prodrome of Parkinson disease: implications for treatment. Nat Rev Neurol 6: 309-317

28. Lesage S, Brice A (2009) Parkinson's disease: from monogenic forms to genetic susceptibility factors. Hum Mol Genet 18:R4859

29. Obeso JA, Rodriguez-Oroz MC, Goetz CG, Marin C, Kordower JH, Rodriguez M, Hirsch EC, Farrer M, Schapira AH, Halliday G (2010) Missing pieces in the Parkinson's disease puzzle. Nat Med 16:653-661

30. Paisan-Ruiz C, Jain S, Evans EW, Gilks WP, Simon J, van der Brug M, Lopez de Munain A, Aparicio S, Gil AM, Khan N et al (2004) Cloning of the gene containing mutations that cause PARK8-linked Parkinson's disease. Neuron 44:595-600

31. Zimprich A, Biskup S, Leitner P, Lichtner P, Farrer M, Lincoln S, Kachergus J, Hulihan M, Uitti RJ, Calne DB et al (2004) Mutations in LRRK2 cause autosomal-dominant parkinsonism with pleomorphic pathology. Neuron 44:601-607

32. Cookson MR (2010) The role of leucine-rich repeat kinase 2 (LRRK2) in Parkinson's disease. Nat Rev Neurosci 11:791-797

33. West AB, Moore DJ, Biskup S, Bugayenko A, Smith WW, Ross CA, Dawson VL, Dawson TM (2005) Parkinson's disease-associated mutations in leucine-rich repeat kinase 2 augment kinase activity. Proc Natl Acad Sci U S A 102:16842-16847

34. Sanchez-Danes A, Richaud-Patin Y, Carballo-Carbajal I, Jimenez-Delgado S, Caig C, Mora S, Di Guglielmo C, Ezquerra M, Patel B, Giralt A et al (2012) Disease-specific phenotypes in dopamine neurons from human iPS-based models of genetic and sporadic Parkinson's disease. EMBO Mol Med 4:380-395

35. Sanchez-Danes A, Consiglio A, Richaud Y, Rodriguez-Piza I, Dehay B, Edel M, Bove J, Memo M, Vila M, Raya A et al (2011) Efficient generation of A9 midbrain dopaminergic neurons by lentiviral delivery of LMX1A in human embryonic stem cells and induced pluripotent stem cells. Hum Gene Ther 23:56-69

36. Su YC, Qi X (2013) Inhibition of excessive mitochondrial fission reduced aberrant autophagy and neuronal damage caused by LRRK2 G2019S mutation. Hum Mol Genet 22:4545-4561

37. Cuervo AM, Stefanis L, Fredenburg R, Lansbury PT, Sulzer D (2004) Impaired degradation of mutant alpha-synuclein by chaperone-mediated autophagy. Science 305:1292-1295

38. Orenstein SJ, Kuo SH, Tasset I, Arias E, Koga H, FernandezCarasa I, Cortes E, Honig LS, Dauer W, Consiglio A et al (2013) Interplay of LRRK2 with chaperone-mediated autophagy. Nat Neurosci 16:394-406

39. Reinhardt P, Schmid B, Burbulla LF, Schondorf DC, Wagner L, Glatza M, Hoing S, Hargus G, Heck SA, Dhingra A et al (2013) Genetic correction of a LRRK2 mutation in human iPSCs links parkinsonian neurodegeneration to ERK-dependent changes in gene expression. Cell Stem Cell 12:354-367

40. Hsieh $\mathrm{CH}$, Shaltouki A, Gonzalez AE, Bettencourt da Cruz A, Burbulla LF, St Lawrence E, Schule B, Krainc D, Palmer TD, Wang X (2016) Functional impairment in Miro degradation and mitophagy is a shared feature in familial and sporadic Parkinson's disease. Cell Stem Cell 19(6):709-724

41. Ohta E, Nihira T, Uchino A, Imaizumi Y, Okada Y, Akamatsu W, Takahashi K, Hayakawa H, Nagai M, Ohyama M et al (2015) I2020T mutant LRRK2 iPSC-derived neurons in the Sagamihara family exhibit increased Tau phosphorylation through the AKT/ GSK-3beta signaling pathway. Hum Mol Genet 24:4879-4900

42. Bjorkoy G, Lamark T, Brech A, Outzen H, Perander M, Overvatn A, Stenmark H, Johansen T (2005) p62/SQSTM1 forms protein 
aggregates degraded by autophagy and has a protective effect on huntingtin-induced cell death. J Cell Biol 171:603-614

43. Sidransky E, Nalls MA, Aasly JO, Aharon-Peretz J, Annesi G, Barbosa ER, Bar-Shira A, Berg D, Bras J, Brice A et al (2009) Multicenter analysis of glucocerebrosidase mutations in Parkinson's disease. N Engl J Med 361:1651-1661

44. Nalls MA, Duran R, Lopez G, Kurzawa-Akanbi M, McKeith IG, Chinnery PF, Morris CM, Theuns J, Crosiers D, Cras P et al (2013) A multicenter study of glucocerebrosidase mutations in dementia with Lewy bodies. JAMA Neurol 70:727-735

45. Siebert M, Sidransky E, Westbroek W (2014) Glucocerebrosidase is shaking up the synucleinopathies. Brain 137:1304-1322

46. Bellettato CM, Scarpa M (2010) Pathophysiology of neuropathic lysosomal storage disorders. J Inherit Metab Dis 33:347-362

47. Bultron G, Kacena K, Pearson D, Boxer M, Yang R, Sathe S, Pastores G, Mistry PK (2010) The risk of Parkinson's disease in type 1 Gaucher disease. J Inherit Metab Dis 33:167-173

48. Goker-Alpan O, Giasson BI, Eblan MJ, Nguyen J, Hurtig HI, Lee VM, Trojanowski JQ, Sidransky E (2006) Glucocerebrosidase mutations are an important risk factor for Lewy body disorders. Neurology 67:908-910

49. Schondorf DC, Aureli M, McAllister FE, Hindley CJ, Mayer F, Schmid B, Sardi SP, Valsecchi M, Hoffmann S, Schwarz LK et al (2014) iPSC-derived neurons from GBA1-associated Parkinson's disease patients show autophagic defects and impaired calcium homeostasis. Nat Commun 5:4028

50. Williams A, Sarkar S, Cuddon P, Ttofi EK, Saiki S, Siddiqi FH, Jahreiss L, Fleming A, Pask D, Goldsmith P et al (2008) Novel targets for Huntington's disease in an mTOR-independent autophagy pathway. Nat Chem Biol 4:295-305

51. Fernandes HJ, Hartfield EM, Christian HC, Emmanoulidou E, Zheng Y, Booth H, Bogetofte H, Lang C, Ryan BJ, Sardi SP et al (2016) ER Stress and Autophagic Perturbations Lead to Elevated Extracellular alpha-Synuclein in GBA-N370S Parkinson's iPSC-Derived Dopamine Neurons. Stem Cell Rep 6:342-356

52. Narendra D, Tanaka A, Suen DF, Youle RJ (2008) Parkin is recruited selectively to impaired mitochondria and promotes their autophagy. J Cell Biol 183:795-803

53. Vives-Bauza C, Zhou C, Huang Y, Cui M, de Vries RL, Kim J, May J, Tocilescu MA, Liu W, Ko HS et al (2010) PINK1-dependent recruitment of Parkin to mitochondria in mitophagy. Proc Natl Acad Sci U S A 107:378-383

54. Narendra DP, Jin SM, Tanaka A, Suen DF, Gautier CA, Shen J, Cookson MR, Youle RJ (2010) PINK1 is selectively stabilized on impaired mitochondria to activate Parkin. PLoS Biol 8:e1000298

55. Valente EM, Abou-Sleiman PM, Caputo V, Muqit MM, Harvey K, Gispert S, Ali Z, Del Turco D, Bentivoglio AR, Healy DG et al (2004) Hereditary early-onset Parkinson's disease caused by mutations in PINK1. Science 304:1158-1160

56. Kitada T, Asakawa S, Hattori N, Matsumine H, Yamamura Y, Minoshima S, Yokochi M, Mizuno Y, Shimizu N (1998) Mutations in the parkin gene cause autosomal recessive juvenile parkinsonism. Nature 392:605-608

57. Geisler S, Holmstrom KM, Skujat D, Fiesel FC, Rothfuss OC, Kahle PJ, Springer W (2010) PINK1/Parkin-mediated mitophagy is dependent on VDAC1 and p62/SQSTM1. Nat Cell Biol 12:119-131

58. Seibler P, Graziotto J, Jeong H, Simunovic F, Klein C, Krainc D (2011) Mitochondrial Parkin recruitment is impaired in neurons derived from mutant PINK1 induced pluripotent stem cells. J Neurosci 31:5970-5976

59. Rakovic A, Shurkewitsch K, Seibler P, Grunewald A, Zanon A, Hagenah J, Krainc D, Klein C (2013) Phosphatase and tensin homolog (PTEN)-induced putative kinase 1 (PINK1)-dependent ubiquitination of endogenous Parkin attenuates mitophagy: study in human primary fibroblasts and induced pluripotent stem cellderived neurons. J Biol Chem 288:2223-2237

60. Shaltouki A, Sivapatham R, Pei Y, Gerencser AA, Momcilovic O, Rao MS, Zeng X (2015) Mitochondrial alterations by PARKIN in dopaminergic neurons using PARK2 patient-specific and PARK2 knockout isogenic iPSC lines. Stem Cell Rep 4:847-859

61. Selkoe DJ (2001) Alzheimer's disease: genes, proteins, and therapy. Physiol Rev 81:741-766

62. Nixon RA, Yang DS (2011) Autophagy failure in Alzheimer's disease-locating the primary defect. Neurobiol Dis 43:38-45

63. Sherrington R, Rogaev EI, Liang Y, Rogaeva EA, Levesque G, Ikeda M, Chi H, Lin C, Li G, Holman K et al (1995) Cloning of a gene bearing missense mutations in early-onset familial Alzheimer's disease. Nature 375:754-760

64. Neely KM, Green KN, LaFerla FM (2011) Presenilin is necessary for efficient proteolysis through the autophagy-lysosome system in a gamma-secretase-independent manner. J Neurosci 31:2781-2791

65. Lee JH, Yu WH, Kumar A, Lee S, Mohan PS, Peterhoff CM, Wolfe DM, Martinez-Vicente M, Massey AC, Sovak G et al (2010) Lysosomal proteolysis and autophagy require presenilin 1 and are disrupted by Alzheimer-related PS1 mutations. Cell 141: $1146-1158$

66. Haughey NJ, Bandaru VV, Bae M, Mattson MP (2010) Roles for dysfunctional sphingolipid metabolism in Alzheimer's disease neuropathogenesis. Biochim Biophys Acta 1801:878-886

67. Grimm MO, Grimm HS, Patzold AJ, Zinser EG, Halonen R, Duering M, Tschape JA, De Strooper B, Muller U, Shen J et al (2005) Regulation of cholesterol and sphingomyelin metabolism by amyloid-beta and presenilin. Nat Cell Biol 7:1118-1123

68. Lee JK, Jin HK, Park MH, Kim BR, Lee PH, Nakauchi H, Carter JE, He X, Schuchman EH, Bae JS (2014) Acid sphingomyelinase modulates the autophagic process by controlling lysosomal biogenesis in Alzheimer's disease. J Exp Med 211:1551-1570

69. Sardiello M, Palmieri M, di Ronza A, Medina DL, Valenza M, Gennarino VA, Di Malta C, Donaudy F, Embrione V, Polishchuk $\mathrm{RS}$ et al (2009) A gene network regulating lysosomal biogenesis and function. Science 325(5939):473-477

70. Settembre C, Di Malta C, Polito VA, Garcia Arencibia M, Vetrini F, Erdin S, Erdin SU, Huynh T, Medina D, Colella P et al (2011) TFEB links autophagy to lysosomal biogenesis. Science 332(6036):1429-1433

71. Reddy K, Cusack CL, Nnah IC, Khayati K, Saqcena C, Huynh TB, Noggle SA, Ballabio A, Dobrowolski R (2016) Dysregulation of nutrient sensing and CLEARance in presenilin deficiency. Cell Rep 14:2166-2179

72. Renton AE, Chio A, Traynor BJ (2014) State of play in amyotrophic lateral sclerosis genetics. Nat Neurosci 17:17-23

73. Petkau TL, Leavitt BR (2014) Progranulin in neurodegenerative disease. Trends Neurosci 37:388-398

74. Ling SC, Polymenidou M, Cleveland DW (2013) Converging mechanisms in ALS and FTD: disrupted RNA and protein homeostasis. Neuron 79:416-438

75. Karageorgiou E, Miller BL (2014) Frontotemporal lobar degeneration: a clinical approach. Semin Neurol 34:189-201

76. Neumann M, Kovacs GG, Mackenzie IRA (2015) Neuropathology of frontotemporal dementia and related disorders. In: Dickerson BC (ed) Hodges' frontotemporal dementia, 2nd edn. Cambridge University Press, Cambridge, pp 165-184

77. DeJesus-Hernandez M, Mackenzie IR, Boeve BF, Boxer AL, Baker M, Rutherford NJ, Nicholson AM, Finch NA, Flynn H, Adamson J et al (2011) Expanded GGGGCC hexanucleotide repeat in noncoding region of C9ORF72 causes chromosome 9plinked FTD and ALS. Neuron 72:245-256

78. Majounie E, Renton AE, Mok K, Dopper EG, Waite A, Rollinson S, Chio A, Restagno G, Nicolaou N, Simon-Sanchez J et al (2012) 
Frequency of the C9orf72 hexanucleotide repeat expansion in patients with amyotrophic lateral sclerosis and frontotemporal dementia: a cross-sectional study. Lancet Neurol 11:323-330

79. Renton AE, Majounie E, Waite A, Simon-Sanchez J, Rollinson S, Gibbs JR, Schymick JC, Laaksovirta H, van Swieten JC, Myllykangas L et al (2011) A hexanucleotide repeat expansion in C9ORF72 is the cause of chromosome 9p21-linked ALSFTD. Neuron 72:257-268

80. Ash PE, Bieniek KF, Gendron TF, Caulfield T, Lin WL, DejesusHernandez M, van Blitterswijk MM, Jansen-West K, Paul JW 3rd, Rademakers R et al (2013) Unconventional translation of C9ORF72 GGGGCC expansion generates insoluble polypeptides specific to c9FTD/ALS. Neuron 77:639-646

81. Mori K, Weng SM, Arzberger T, May S, Rentzsch K, Kremmer E, Schmid B, Kretzschmar HA, Cruts M, Van Broeckhoven C et al (2013) The C9orf72 GGGGCC repeat is translated into aggregating dipeptide-repeat proteins in FTLD/ALS. Science 339:1335-1338

82. Almeida S, Gascon E, Tran H, Chou HJ, Gendron TF, Degroot S, Tapper AR, Sellier C, Charlet-Berguerand N, Karydas A et al (2013) Modeling key pathological features of frontotemporal dementia with C9ORF72 repeat expansion in iPSC-derived human neurons. Acta Neuropathol 126:385-399

83. Sellier C, Campanari ML, Julie Corbier C, Gaucherot A, KolbCheynel I, Oulad-Abdelghani M, Ruffenach F, Page A, Ciura S, Kabashi E et al (2016) Loss of C9ORF72 impairs autophagy and synergizes with polyQ Ataxin-2 to induce motor neuron dysfunction and cell death. EMBO J 35:1276-1297

84. Toh H, Chitramuthu BP, Bennett HP, Bateman A (2011) Structure, function, and mechanism of progranulin; the brain and beyond. J Mol Neurosci 45:538-548

85. Gass J, Lee WC, Cook C, Finch N, Stetler C, Jansen-West K, Lewis J, Link CD, Rademakers R, Nykjaer A et al (2012) Progranulin regulates neuronal outgrowth independent of sortilin. Mol Neurodegener 7:33

86. Smith KR, Damiano J, Franceschetti S, Carpenter S, Canafoglia L, Morbin M, Rossi G, Pareyson D, Mole SE, Staropoli JF et al (2012) Strikingly different clinicopathological phenotypes determined by progranulin-mutation dosage. Am J Hum Genet 90:1102-1107

87. Sarkar S, Davies JE, Huang Z, Tunnacliffe A, Rubinsztein DC (2007) Trehalose, a novel mTOR-independent autophagy enhancer, accelerates the clearance of mutant huntingtin and alpha-synuclein. J Biol Chem 282:5641-5652

88. Holler CJ, Taylor G, McEachin ZT, Deng Q, Watkins WJ, Hudson K, Easley CA, Hu WT, Hales CM, Rossoll W et al (2016) Trehalose upregulates progranulin expression in human and mouse models of GRN haploinsufficiency: a novel therapeutic lead to treat frontotemporal dementia. Mol Neurodegener 11:46

89. Morris M, Maeda S, Vossel K, Mucke L (2011) The many faces of tau. Neuron 70:410-426

90. Lee SE, Tartaglia MC, Yener G, Genc S, Seeley WW, SanchezJuan P, Moreno F, Mendez MF, Klein E, Rademakers R et al (2013) Neurodegenerative disease phenotypes in carriers of MAPT p.A152T, a risk factor for frontotemporal dementia spectrum disorders and Alzheimer disease. Alzheimer Dis Assoc Disord 27:302-309

91. Coppola G, Chinnathambi S, Lee JJ, Dombroski BA, Baker MC, Soto-Ortolaza AI, Lee SE, Klein E, Huang AY, Sears R et al (2012) Evidence for a role of the rare p.A152T variant in MAPT in increasing the risk for FTD-spectrum and Alzheimer's diseases. Hum Mol Genet 21:3500-3512

92. Silva MC, Cheng C, Mair W, Almeida S, Fong H, Biswas MH, Zhang Z, Huang Y, Temple S, Coppola G et al (2016) Human iPSC-Derived Neuronal Model of Tau-A152T Frontotemporal
Dementia Reveals Tau-Mediated Mechanisms of Neuronal Vulnerability. Stem Cell Rep 7:325-340

93. Wang Y, Martinez-Vicente M, Kruger U, Kaushik S, Wong E, Mandelkow EM, Cuervo AM, Mandelkow E (2009) Tau fragmentation, aggregation and clearance: the dual role of lysosomal processing. Hum Mol Genet 18:4153-4170

94. Carstea ED, Morris JA, Coleman KG, Loftus SK, Zhang D, Cummings C, Gu J, Rosenfeld MA, Pavan WJ, Krizman DB et al (1997) Niemann-Pick C1 disease gene: homology to mediators of cholesterol homeostasis. Science 277:228-231

95. Vanier MT (2010) Niemann-Pick disease type C. Orphanet J Rare Dis 5:16

96. Singh R, Kaushik S, Wang Y, Xiang Y, Novak I, Komatsu M, Tanaka K, Cuervo AM, Czaja MJ (2009) Autophagy regulates lipid metabolism. Nature 458(7242):1131-1135

97. Singh R, Cuervo AM (2012) Lipophagy: connecting autophagy and lipid metabolism. Int J Cell Biol 2012:282041

98. Maetzel D, Sarkar S, Wang H, Abi-Mosleh L, Xu P, Cheng AW, Gao Q, Mitalipova M, Jaenisch R (2014) Genetic and chemical correction of cholesterol accumulation and impaired autophagy in hepatic and neural cells derived from NiemannPick Type C patient-specific iPS cells. Stem Cell Rep 2(6): 866-880

99. Lee H, Lee JK, Park MH, Hong YR, Marti HH, Kim H, Okada Y, Otsu M, Seo EJ, Park JH et al (2014) Pathological roles of the VEGF/SphK pathway in Niemann-Pick type C neurons. Nat Commun 5:5514

100. Soga M, Ishitsuka Y, Hamasaki M, Yoneda K, Furuya H, Matsuo M, Ihn H, Fusaki N, Nakamura K, Nakagata N et al (2015) HPGCD outperforms HPBCD as a potential treatment for Niemann-Pick disease type $\mathrm{C}$ during disease modeling with iPS cells. Stem Cells 33(4):1075-1088

101. Hockemeyer D, Jaenisch R (2016) Induced pluripotent stem cells meet genome editing. Cell Stem Cell 18:573-586

102. Chen H, Qian K, Du Z, Cao J, Petersen A, Liu H, Blackbourn LW, Huang CL, Errigo A, Yin Y et al (2014) Modeling ALS with iPSCs reveals that mutant SOD1 misregulates neurofilament balance in motor neurons. Cell Stem Cell 14:796-809

103. Mizushima N, Yoshimori T, Levine B (2010) Methods in mammalian autophagy research. Cell 140:313-326

104. Klionsky DJ, Abdelmohsen K, Abe A, Abedin MJ, Abeliovich H, Acevedo Arozena A, Adachi H, Adams CM, Adams PD, Adeli K et al (2016) Guidelines for the use and interpretation of assays for monitoring autophagy (3rd edition). Autophagy 12:1-222

105. Cortes CJ, Miranda HC, Frankowski H, Batlevi Y, Young JE, Le A, Ivanov N, Sopher BL, Carromeu C, Muotri AR et al (2014) Polyglutamine-expanded androgen receptor interferes with TFEB to elicit autophagy defects in SBMA. Nat Neurosci 17(9):1180-1189

106. HD iPSC Consortium (2012) Induced pluripotent stem cells from patients with Huntington's disease show CAG-repeatexpansion-associated phenotypes. Cell Stem Cell 11(2):264 278

107. Koch P, Breuer P, Peitz M, Jungverdorben J, Kesavan J, Poppe D, Doerr J, Ladewig J, Mertens J, Tuting T et al (2011) Excitation-induced ataxin-3 aggregation in neurons from patients with Machado-Joseph disease. Nature 480(7378):543-546

108. Komatsu M, Wang QJ, Holstein GR, Friedrich VL Jr, Iwata J, Kominami E, Chait BT, Tanaka K, Yue Z (2007) Essential role for autophagy protein Atg7 in the maintenance of axonal homeostasis and the prevention of axonal degeneration. Proc Natl Acad Sci U S A 104:14489-14494

109. Friedman LG, Lachenmayer ML, Wang J, He L, Poulose SM, Komatsu M, Holstein GR, Yue Z (2012) Disrupted autophagy leads to dopaminergic axon and dendrite degeneration and 
promotes presynaptic accumulation of alpha-synuclein and LRRK2 in the brain. J Neurosci 32:7585-7593

110. Miller JD, Ganat YM, Kishinevsky S, Bowman RL, Liu B, Tu EY, Mandal PK, Vera E, Shim JW, Kriks S et al (2013) Human iPSCbased modeling of late-onset disease via progerin-induced aging. Cell Stem Cell 13:691-705

111. Yamamoto A (2014) Yue Z (2014). Autophagy and its normal and pathogenic states in the brain. Annu Rev Neurosci 37:55-78
112. Schwarz L, Goldbaum O, Bergmann M, Probst-Cousin S, RichterLandsberg C (2012) Involvement of macroautophagy in multiple system atrophy and protein aggregate formation in oligodendrocytes. J Mol Neurosci 47(2):256-66

113. Tanji K, Odagiri S, Maruyama A, Mori F, Kakita A, Takahashi H, Wakabayashi K (2013) Alteration of autophagosomal proteins in the brain of multiple system atrophy. Neurobiol Dis 49:190-8 